\title{
Differential lectin labelling of circulating hemocytes from Biomphalaria glabrata and Biomphalaria tenagophila resistant or susceptible to Schistosoma mansoni infection
}

\author{
RL Martins-Souza, CAJ Pereira, OA Martins Filho*, PMZ Coelho*, A Corrêa Jr**, \\ D Negrão-Corrêa/ ${ }^{+}$
}

Departamento de Parasitologia **Departamento de Microbiologia, ICB, UFMG, Av. Antônio Carlos 6627, 31270-901 Belo
Horizonte, MG, Brasil *Centro de Pesquisa René-Rachou-Fiocruz, Belo Horizonte, MG, Brasil

Lectins/carbohydrate binding can be involved in the Schistosoma mansoni recognition and activation of the Biomphalaria hemocytes. Therefore, expression of lectin ligands on Biomphalaria hemocytes would be associated with snail resistance against $\mathrm{S}$. mansoni infection. To test this hypothesis, circulating hemocytes were isolated from B. glabrata BH (snail strain highy susceptible to S. mansoni), B. tenagophila Cabo Frio (moderate susceptibility), and B. tenagophila Taim (completely resistant strains), labelled with FITC conjugated lectins (ConA, PNA, SBA, and WGA) and analyzed under fluorescence microscopy. The results demonstrated that although lectin-labelled hemocytes were detected in hemolymph of all snail species tested, circulating hemocytes from both strains of B. tenagophila showed a larger number of lectin-labelled cells than B. glabrata. Moreover, most of circulating hemocytes of B. tenagophila were intensively labelled by lectins PNA-FITC and WGA-FITC, while in B. glabrata small hemocytes were labeled mainly by ConA. Upon S. mansoni infection, lectin-labelled hemocytes almost disappeared from the hemolymph of Taim and accumulated in B. glabrata BH. The role of lectins/carbohydrate binding in resistance of $\mathrm{B}$. tengophila infection to $\mathrm{S}$. mansoni is still not fully understood, but the data suggest that there may be a correlation to its presence with susceptibility or resistance to the parasite.

Key words: Schistosoma mansoni - Biomphalaria tenagophila - snail susceptibility to trematode - lectin labelling of hemocytes host-parasite interaction

Some snail species of the genus Biomphalaria are obligatory hosts for the development of the larval stages of Schistosoma mansoni life cycle. The capacity of the inner defense system (IDS) of that host to destroy the parasite is one of the factors that may determinate Biomphalaria susceptibility to $S$. mansoni infection (Souza et al. 1997, Yoshino et al. 2001, Martins-Souza et al. 2003). The IDS of Biomphalaria remains not completely understood, but it is well known that it is composed of cellular elements named hemocytes, and soluble components that could directly affect the larvae and/or act on the recognition of the parasite and activation of hemocytes.

Hemocytes are the main mediators of the defense system of molluscs, taking part in phagocytosis of particles (e.g. bacteria and protozoans), as well as in encapsulation of larger parasites, as for example helminthic larvae (van der Knaap \& Loker 1990). Nevertheless, participation of the soluble fraction of $B$. glabrata hemolymph (Granath $\&$ Yoshino 1984) or of B. tenagophila (Pereira 2005) in the mechanism of destruction of $S$. mansoni sporocysts is also important. This was confirmed in vivo by the increase of resistance to the parasite in susceptible snails treated with hemolymph of resistant ones.

Financial support: Pronex/CNPq, Fapemig ${ }^{+}$Corresponding author: denegrao@icb.ufmg.br Received 25 May 2006

Accepted 26 June 2006
The presence of substances in B. glabrata hemolymph that promote agglutination of hemocytes surrounding $S$. mansoni sporocysts was reported by Loker et al. (1984). Afterwards, Fryer and Bayne (1996) demonstrated that particles of polystyrene treated with soluble factors of hemolymph from resistant strains of B. glabrata are more significantly phagocytized by hemocytes from susceptible strains than the untreated particles, thus suggesting that soluble factors of hemolymph participate in the recognition mechanism and opsonization of particles by hemocytes.

In the search for possible mediators related to the parasite's recognition mechanism, it was demonstrated that purified lectins of Conavalia ensiformis (ConA), Erythrina corallodendrom (ECA), Glycine max (SBA), Tetragonolobus purpurea (TPA), and Triticum vulgaris, among others, were able to bind to proteins present on the surface of S. mansoni sporocysts (Yoshino 1976, Uchikawa \& Loker 1991, Johnston \& Yoshino, 1996). Johnston and Yoshino (1996) showed that proteins from the soluble fraction of $B$. glabrata hemolymph were also capable of binding to the majority of sporocyst proteins recognized by purified lectins. Binding of these hemolymph proteins was strongly inhibited when sporocyst proteins were treated with periodate, suggesting participation of carbohydrates in this interaction. Thus, lectins could functionally intermediate binding of hemocytes to the larval tegument of trematodes (van der Knaap \& Loker 1990). Moreover, the binding lectin-carbohydrate possibly leads to a structural change of the complex, that could induce hemocyte activation (Bayne 1990), resulting in an 
increase of the phagocitary activity (Fryer et al. 1989) and/ or of production of reactive oxygen derivatives (ROI) (Hahn et al. 2000). For this reason, the resistance or susceptibility of species or strains of Biomphalaria to $S$. mansoni infection could be related to qualitative or quantitative differences in the production of some lectins (Zelck \& Becker 1990). Nevertheless, various experiments showed no difference in lectin composition of hemolymph from susceptible and resistant strains of Biomphalaria (Johnston \& Yoshino 1996).

In molluscs, lectins are synthesized by hemocytes and released in hemolymph, or are expressed on the surface of circulating hemocytes, where they are able to act as cytophylic receptors (Richards \& Renwrantz 1991). Thus, another possibility that has been poorly explored in the literature is that differences in the recognition of the parasite could be related to differences in the expression of lectin ligands in hemocytes of different snail strains. Therefore, the objective of this experimental study was to verify lectin binding on circulating hemocytes from $B$. glabrata $\mathrm{BH}$, a snail strain that is highly susceptible to $S$. mansoni infection (Paraense \& Corrêa 1963), as well as in hemocytes from $B$. tenagophila Cabo Frio, snail strain with moderate susceptility to $S$. mansoni, and B. tenagophila Taim that is completely resistant to the parasite infection (Martins-Souza et al. 2003). Moreover, we intent to verify if the resistance of $B$. tenagophila Taim to $S$. mansoni would be associated with the variation of expression of lectin-hapten on the circulating hemocytes.

\section{MATERIALS AND METHODS}

Parasite - The snails above mentioned were infected with $S$. mansoni of LE strain (isolated from a patient at Belo Horizonte, MG, Brazil). This strain has been maintained at the laboratory of the Schistosomiasis Research Unit, Federal University of Minas Gerais, Brazil, for 35 years.

Snails - Snail species of B. glabrata and B. tenagophila used in this study has been bred and maintained according to the procedures previously described by Pellegrino and Katz (1968) at the mollusc room of the Schistosomiasis Research Unit, Institute of Biological Sciences, Federal University of Minas Gerais, Brazil, for at least 25 years. The lineage of B. glabrata utilized and named $\mathrm{BH}$ strain proceeds from the Pampulha lake, Belo Horizonte, MG, Brazil. This snail strain is highly susceptible to the infection to $S$. mansoni (Paraense \& Corrêa 1963). Two strains of $B$. tenagophila were selected for the study. The Taim strain collected at the Ecological Station of Taim, Rio Grande do Sul, Brazil, and the Cabo Frio strain collected at Cabo Frio, Rio de Janeiro, Brazil. B. tenagophila Taim is totally resistant to $S$. mansoni infection, LE or SJ strain (Santos et al. 1979, Martins-Souza et al. 2003), while Cabo Frio strain is highly susceptible to $S$. mansoni SJ and is partially resistant to $S$. mansoni LE (Corrêa et al. 1979, Martins-Souza et al. 2003).

Infection of snails - Hamsters (Mesocricetus auratus) infected with the LE strain of S. mansoni were sacrificed 45-50 days after infection, for obtention of miracidia. The snails were individually infected with 20 miracidia, accord- ing to the technique described by Pellegrino and Katz (1968). Snails with 12-14 mm diameter in size were used in all experiments, at the moment of infection.

Labelling of molecules expressed on the surface of circulating hemocytes - Labelling on the surface of circulating hemocytes from different strains of Biomphalaria was performed with lectins isolated from Concanavalin A - ConA, Glycine max - SBA, Triticum vulgaris - WGA and Arachis hypogaea - PNA conjugated with fluorescein isothyocynate - FITC (EY Laboratories, San Mateo). The cells presenting fluorescence after treatment were considered as labelled.

Circulating hemocytes were isolated from the total hemolymph collected, by means of cardiac puncture, from B. glabrata or B. tenagophila (Cabo Frio and Taim), uninfected, and after 5, 24, 72, and $120 \mathrm{~h}$ post-infection with 20 miracidia of $S$. mansoni, according to the technique described by Martins-Souza et al. (2003).

At each experimental point, as well as for each snail strain, analyses were performed with hemocytes, collected and gathered together, from the total hemolymph of 15 snails. Hemocytes present in each group were separated from the hemolymph by centrifugation $(200 \times \mathrm{g}$ for $5 \mathrm{~min}$, at room temperature), washed with Chernin's balanced salt solution-CBSS (Chernin 1970), glycose and trealosefree (incomplete CBSS). After that, the sediment of hemocytes was resuspended into $1 \mathrm{ml}$ incomplete CBSS, containing $2 \%$ bovine albumin. A sample of each group was diluted into $1 / 10 \mathrm{CBSS}$ containing $0.4 \%$ Trypan Blue. Total counting and cellular viability of each sample were estimated in Neubauer's chamber. It was observed that the hemocytes used showed more than $90 \%$ viability. Throughout countings, the hemocytes were morphologically classified as small, medium, and large.

Each treatment was carried out in triplicate using $1 \times$ $10^{5}$ hemocytes for each replica, the hemocytes being distributed into $1.5-\mathrm{ml}$ polypropilene tubes. Simultaneously, a control was performed with $1 \times 10^{5}$ hemocytes, in triplicate, for each labelling in relation to the lectin-hemocyte specificity. After distribution of hemocytes, the tubes were centrifuged $(200 \times \mathrm{g}$ for $3 \mathrm{~min})$, the cells resuspended in $200 \mu \mathrm{l}$ incomplete CBSS containing $2 \%$ bovine albumin and $10 \mu \mathrm{g} / \mathrm{ml}$ lectin conjugated with FITC (Con A-FITC, WGA-FITC, SBA-FITC or PNA-FITC), and incubated at room temperature, in the dark, for $1 \mathrm{~h}$. The labelled hemocytes in the control tubes were centrifuged and resuspended in incomplete CBSS containing $0.2 \mathrm{M}$ of specific carbohydrates for each lectin. Mannose was the carbohydrate used for treatments with Con A-FITC, whereas $\mathrm{N}$-acetyl-glycosamine was utilized for treatments with WGA-FITC and D-galactose in the competition trials with the lectins PNA-FITC and SBA-FITC.

After incubation with labelled lectins and addition of carbohydrates related to the control treatments, the hemocytes were washed and resuspended in $100 \mu \mathrm{l}$ incomplete CBSS for analysis under epifluorescence microscope using the appropriate filters (Olympus IX70). A representative number of digital images of hemocytes were obtained from each treatment by means of a digital camera Optronics model DEI-470 and the processing image 
software Image Pro-Plus 5.0. For each treatment, digital images were used to analyze at least 100 hemocytes, defining cell type (small, medium or large) and presence of label.

Statistical analysis - The results obtained were statistically analyzed, using analysis of variance or Student's $t$ test for the parametric data, as well as Krushal-Wallis test for non-parametric data.

\section{RESULTS}

Circulating hemocytes isolated from $B$. glabrata $(\mathrm{BH}$ strain) and B. tenagophila (Cabo Frio and Taim strain) expressed ligands that were able to bind to tested lectins Con A, WGA, SBA, and PNA. However, the proportion of labelled hemocytes in relation to each tested lectin was statistically different concerning the species and strains of Biomphalaria (Fig. 1). Specifically, about $50 \%$ hemocytes from uninfected B. glabrata and B. tenagophila Cabo Frio were labelled by ConA, however a statistically lower rate $(30 \%)$ of circulating hemocytes from $B$. tenagophila Taim presented carbohydrates recognized by ConA. In contrast, the proportion of circulating hemocytes labelled with PNA-FITC was statistically higher in hemocytes isolated from B. tenagophila Taim (64\% of the total) compared with the result obtained in hemocytes from B. tenagophila Cabo Frio and B. glabrata (24 and $10 \%$ of total circulating hemocytes, respectively), and similar pattern was also observed in circulating hemocytes labeled by SBA. Finally, the proportion of circulating hemocytes labelled by WGA-FITC was high, mainly in cells isolated from B. tenagophila $(70-75 \%$ of cells).

Specificity of lectin binding to hemocytes was confirmed by addition of concentrated carbohydrate solution: Mannose for Con A, N-acetylglycosamine for WGA, and Galactosamine for PNA or SBA. In all cases, treatment with the corresponding carbohydrate presented as a result elimination or significant reduction of the fluoresce labelling of hemocytes.

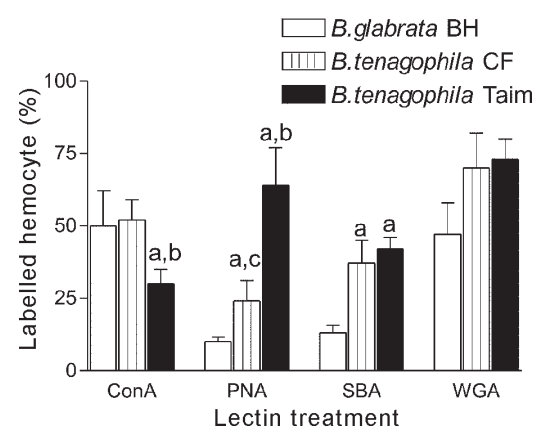

Fig. 1: percentage of total circulating hemocytes isolated from non-infected Biomphalaria glabrata $\mathrm{BH}$ strain, B. tenagophila Cabo Frio strain, and B. tenagophila Taim strain, labeled by FITC conjugated ConA, PNA, SBA or WGA purified lectins. a: represents a value significantly different from the value obtained with hemocytes from $B$. glabrata $\mathrm{BH}$; b: represents a value significantly different $(\mathrm{p}<0.05)$ from the value obtained with hemocytes from $B$. tenagophila Cabo Frio, and c: represents a value significantly different from the value obtained with hemocytes from $B$. tenagophila Taim.
Besides the difference in the proportion of hemocytes labelled by different lectins, it was possible to observe that there were differences in the labelling pattern and in the morphological type of labelled hemocytes between the different strains or species of tested Biomphalaria. In hemocytes isolated from uninfected $B$. glabrata, a diffuse and weak labelling of the cells could be observed, being lectins WGA-FITC (Fig. 2a, b) and Con A-FITC (Fig. $2 \mathrm{c}, \mathrm{d})$ bound to carbohydrates on the surface of small and medium hemocytes, whereas only few small cells were labelled by PNA-FITC (Fig. 2e, f). In contrast, hemocytes isolated from uninfected $B$. tenagophila (Taim and Cabo Frio) showed a more intense label than in B. glabrata, with large cells presenting a strong labelling on the membrane by WGA (Figs 3b, 4b), while small circulating hemocytes were diffused labeled by ConA (Fig. 3d). Another marked difference was the high number of large and medium hemocytes labelled by PNA-FITC, especially in B. tenagophila Taim (Fig. 4c).

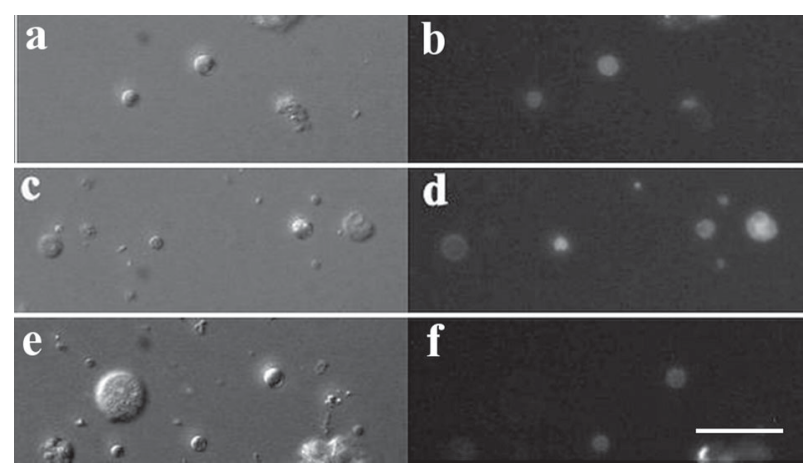

Fig. 2: labelling pattern of circulating hemocytes isolated from non-infected Biomphalaria glabrata BH strain, after incubation with FITC conjugated purified lectins. a and b: hemocytes labeled with WGA-FITC; $c$ and d: hemocytes labeled with PNA-FITC; e and f: hemocytes labeled with ConA-FITC; a, c, and e show the cells on Nomarski microscopy while $\mathrm{b}, \mathrm{d}$, and f represents the same field on fluorescence mycroscopy $(\mathrm{Bar}=10 \mu \mathrm{m})$.

Attempting to verify variations on the surface of circulating hemocytes that could alter the binding of lectins during $S$. mansoni infection, hemocytes were isolated from different species and strains of Biomphalaria, after the first $120 \mathrm{~h}$ post-infection, and incubated with lectin conjugated with FITC. S. mansoni infection induced an increase in the proportion of hemocytes from B. glabrata labelled by Con A. The increase occurred between 5 and $24 \mathrm{hpi}$, as a consequence of the higher number of small and medium labelled hemocytes. After $72 \mathrm{hpi}$, the proportion of hemocytes labelled by ConA decreased to a similar level of that observed in uninfected snails. However, only small hemocytes showed labelling, while medium and large ones labelled by lectin were nearly not observed. Reduction in the proportion of circulating hemocytes from B. glabrata labelled by Con A was more intense after 120 hpi (Fig. 5a). S. mansoni infection also induced a little increase in the proportion of B. glabrata hemocytes la- 

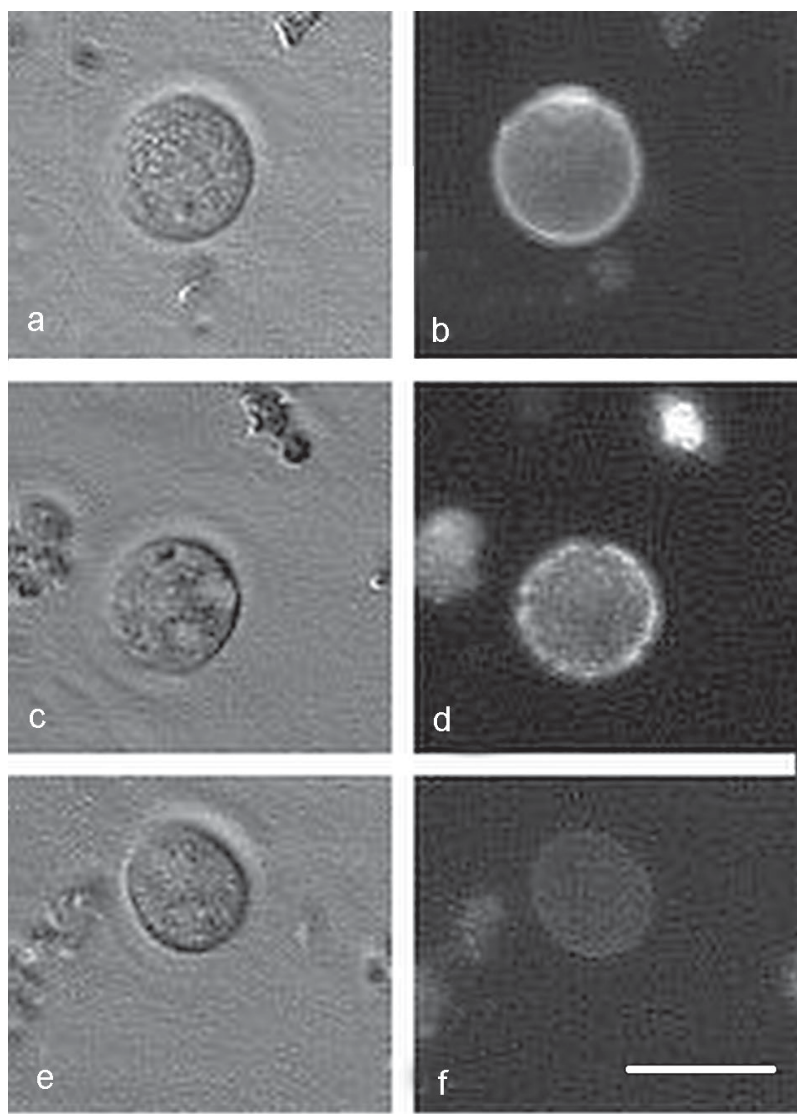

Fig. 3: labelling pattern of circulating hemocytes isolated from non-infected Biomphalaria tenagophila Cabo Frio strain, after incubation with FITC conjugated purified lectins. a and b: hemocytes labeled with WGA-FITC; $c$ and d: hemocytes labeled with PNAFITC; e and f: hemocytes labeled with ConA-FITC; a, c, and e show the cells on Nomarski microscopy while $b, d$, and $f$ represents the same field on fluorescence mycroscopy $($ Bar $=10 \mu \mathrm{m})$.

belled by PNA-FITC and SBA-FITC, being this labelling almost exclusively due to small hemocytes, and that increase was maintained high throughout the observation period (Fig. 5b, c). Analyzing the labelling pattern of $B$. glabrata hemocytes by WGA-FITC, it was observed a high number of labelled cells, being most of them represented by small hemocytes. Nevertheless, the number of medium and large hemocytes that were labelled by WGA was considerably higher than the number of hemocytes labelled by other lectins. During infection, it was detected a decrease in the number of medium hemocytes labelled after $5 \mathrm{~h}$ post-infection, as well as an increase in the number of large hemocytes labelled after $72 \mathrm{~h}$ (Fig. 5d).

$S$. mansoni infection did not increase the proportion of circulating hemocytes isolated from B. tenagophila (Cabo Frio strain) and labelled by ConA-FITC (Fig. 6a) or by WGA-FITC (Fig. 6d). However, it was observed that there was an increase in the proportion of hemocytes labelled by PNA-FITC and SBA-FITC, as a result of the increase in small hemocytes that expressed ligands to these lectins (Fig. 6b, c). Moreover, it is interesting to note that large hemocytes labelled by PNA and WGA nearly disap-
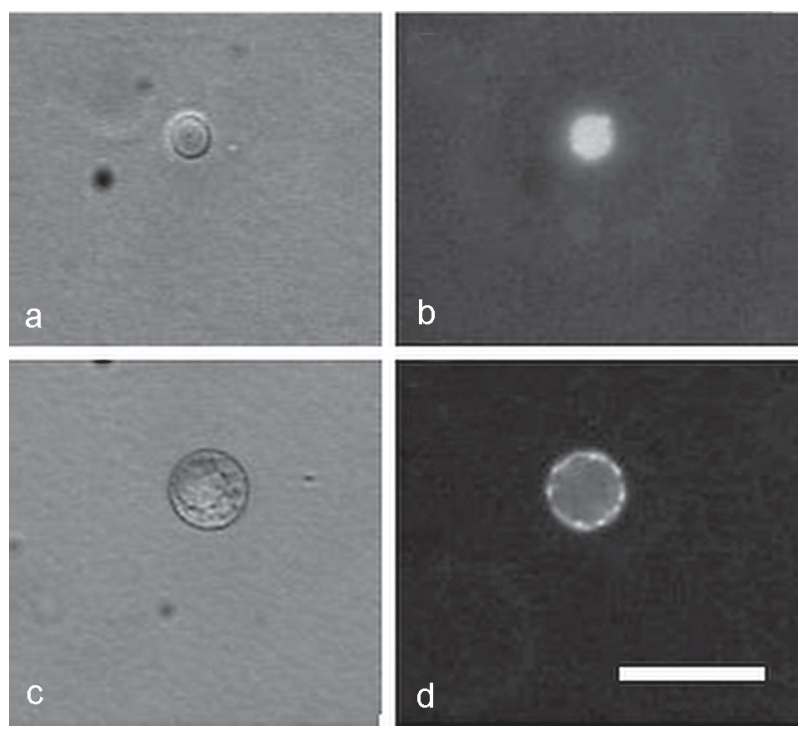

Fig. 4: labelling pattern of circulating hemocytes isolated from non-infected Biomphalaria tenagophila Taim strain, after incubation with FITC conjugated purified lectins. a and b: hemocytes labeled with WGA-FITC; $\mathrm{c}$ and d: hemocytes labeled with PNAFITC; a and c show the cells on Nomarski microscopy while panels $\mathrm{b}$ and $\mathrm{d}$ represents the same field on fluorescence mycroscopy (Bar $=10 \mu \mathrm{m})$

peared from circulation after $5 \mathrm{~h}$ post-infection. Conversely, the proportion of circulating hemocytes labelled by ConA-FITC, PNA-FITC, SBA-FITC, and WGA-FITC decreased after $5 \mathrm{~h}$ post-infection with $S$. mansoni in $B$. tenagophila Taim (Fig. 7). Only in labelling by ConA it could be observed an increase in the proportion of hemocytes labelled after 24 and $72 \mathrm{hpi}$, in relation to noninfected snails (Fig. 7a).

\section{DISCUSSION}

Various authors demonstrated that circulating hemocytes in hemolymph of Biomphalaria is a heterogeneous cell population. Heterogenity of these cells was confirmed morphologically (Sminia 1981, Joky et al. 1983, Barraco et al. 1993, Bezerra et al. 1997, Matricon-Gondran \& Letorcart 1999, Johnston \& Yoshino 2001), and functionally (Granath \& Yoshino 1983, Matricon-Gondran \& Letorcart 1999b, Martins-Souza et al. 2003). Our results confirmed that circulating hemocytes express ligands (carbohydrates) for lectin binding in a very heterogeneous manner. It is interesting to note that the results demonstrated a great variety detected in the pattern and in the type of binding of lectins in hemocytes from B. glabrata when compared to B. tenagophila. A high proportion of hemocytes isolated from $B$. tenagophila showed a marked labelling by different types of lectin, specially PNA and WGA, whereas in circulating hemocytes of $B$. glabrata only incubation with ConA presented as a result a high proportion of labelled cells. Some differences were also detected in the labelling pattern of circulating hemocytes isolated from Cabo Frio and Taim strains. Binding between lectins and the surface of hemocytes showed to be specific, since labelling 
was inhibited by a high concentration of the corresponding carbohydrate.

Histological studies carried out with different strains of infected B. glabrata or B. tenagophila has documented that in highly susceptible molluscs there are sporocysts and cercariae in abundance in the host's tissue, and an
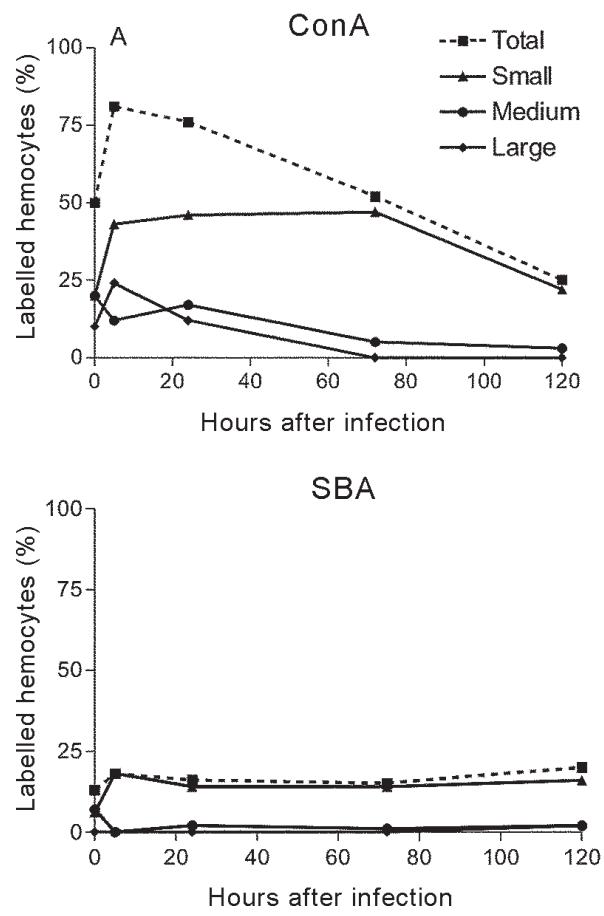

early absolute lack of cellular reaction around the parasite. At the other extreme, there are resistant snails, shedding fewer cercariae, but showing an intense hemocyte infiltration in the host's tissue, frequently found around parasitary structures under disintegration (Guaraldo et al. 1981, Sullivan \& Richards 1981, Souza et al. 1995, 1997).
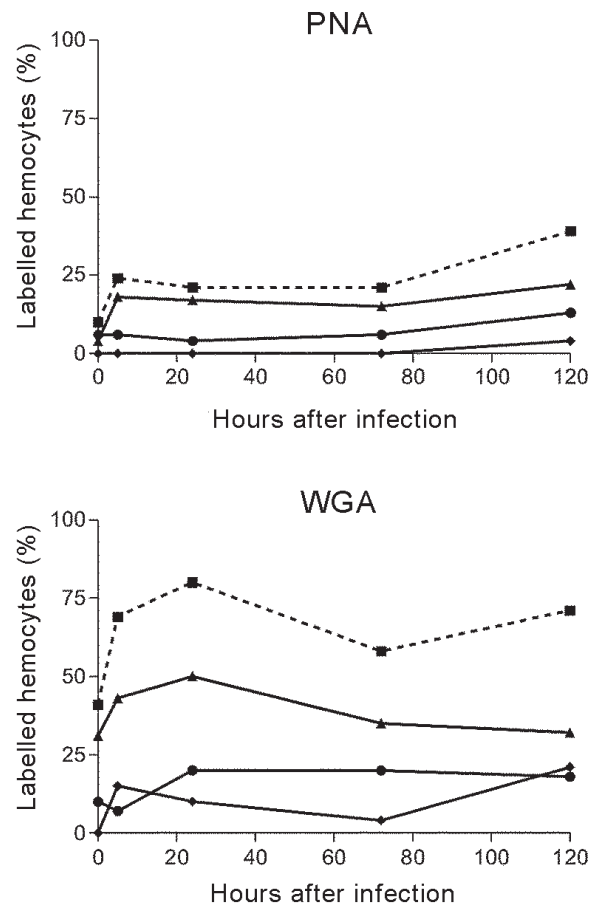

Fig. 5: kinectics of labelled hemocytes of Biomphalaria glabrata BH strain, after incubation with FITC conjugated purified lectins, during the first $120 \mathrm{~h}$ of Schistosoma mansoni infection.
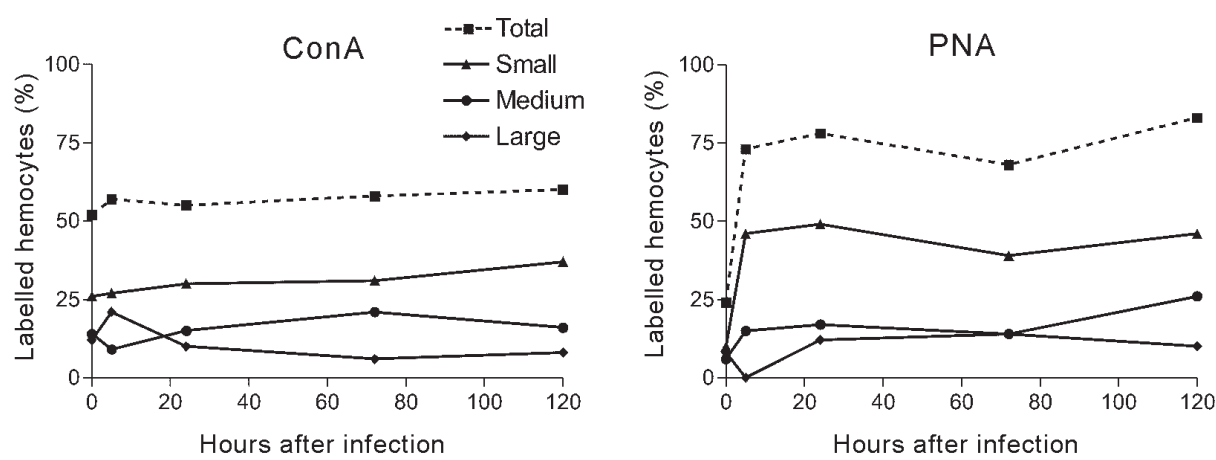

SBA
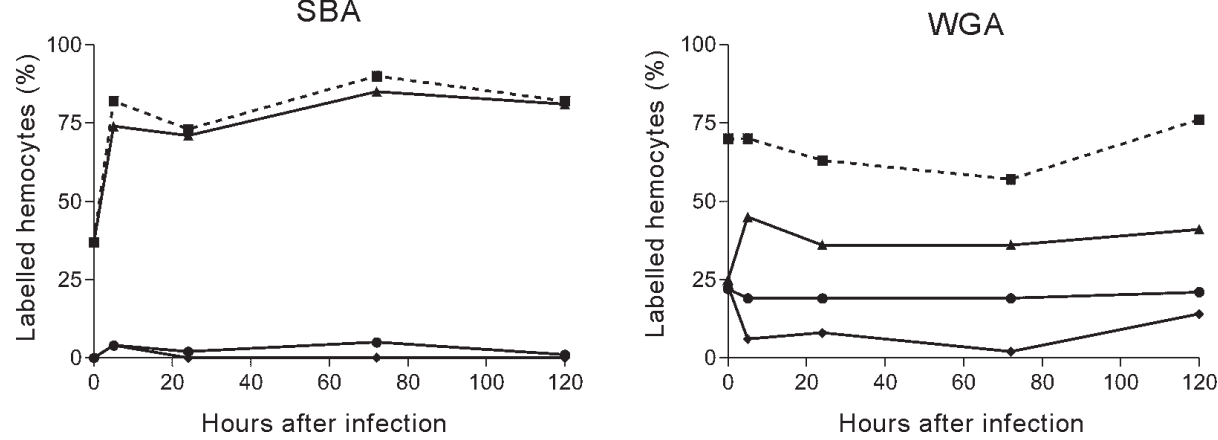

Fig. 6: kinectics of labelled hemocytes of Biomphalaria tenagophila Cabo Frio strain, after incubation with FITC conjugated purified lectins, during the first $120 \mathrm{~h}$ of Schistosoma mansoni infection. 

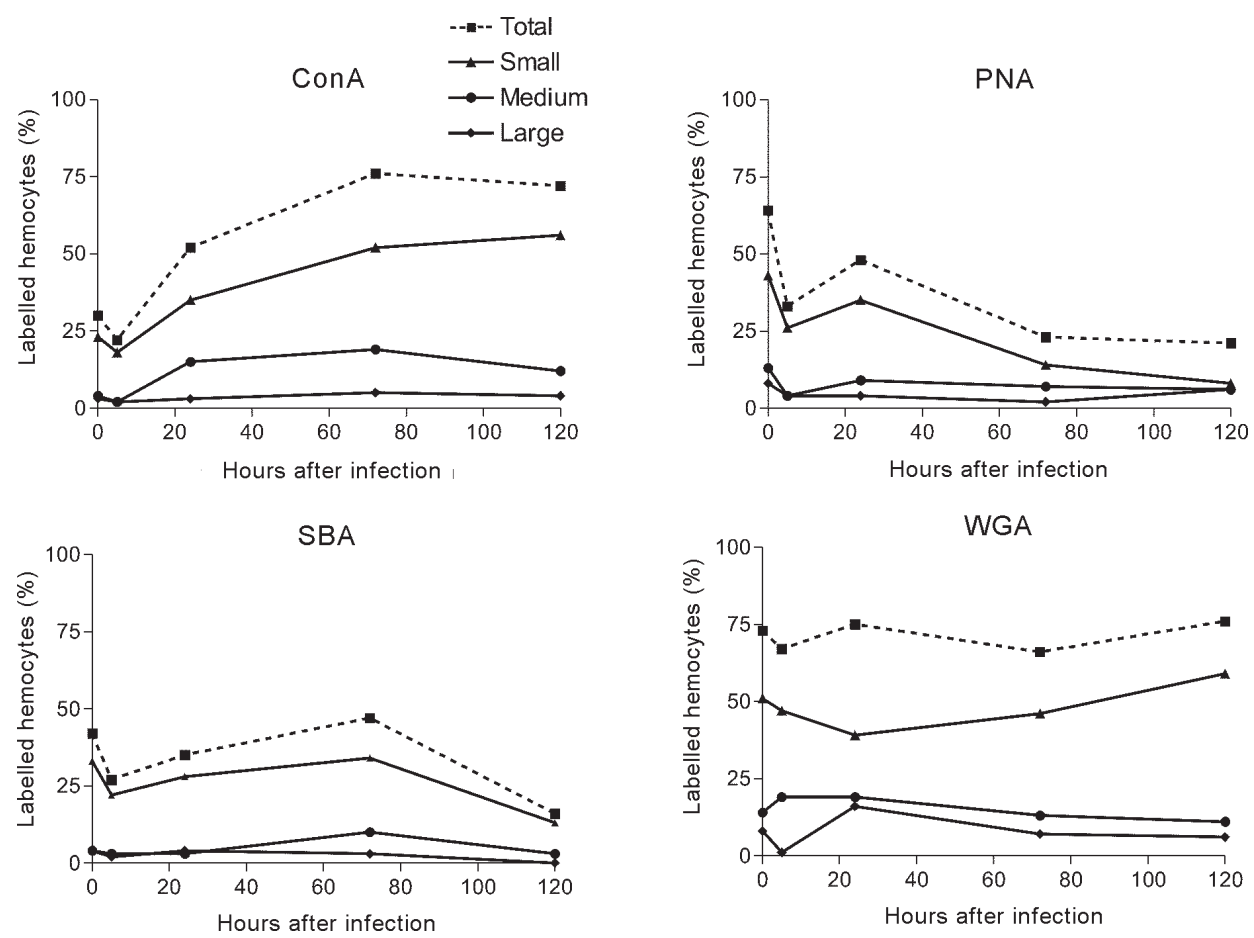

Fig. 7: kinectics of labelled hemocytes of Biomphalaria tenagophila Taim strain, after incubation with FITC conjugated purified lectins, during the first $120 \mathrm{~h}$ of Schistosoma mansoni infection.

Therefore, the significant variation on labelling pattern by lectin observed among different species and strains of Biomphalaria used in this study could help to explain hemocyte binding around the parasite observed in some snail strain and, therefore it would be an important factor for determination of differences in the susceptibility level to $S$. mansoni infection reported in the snail species (Corrêa et al. 1979, Martins-Souza et al. 2003, Coelho et al. 2004, Pereira 2005, Rosa et al. 2005).

Lectin/carbohydrate binding has been associated with recognition of trematode larvae, and could exert influence upon the hemocyte capacity of encapsulating trematode larvae (van der Knaap \& Lokert 1990, Yoshino et al. 2001, Guillou et al. 2004). In this sense, various authors demonstrated that the tegument, at the larval stages of trematodes, is coated with a high level of glycosidic compounds, and the majority of the tested lectins were specifically able to bind either to axenically transformed larvae (Uchikawa \& Loker 1991) or to proteins isolated from its tegument (Johnston \& Yoshino 1996). On the other hand, the presence of lectins has been detected in hemolymph of Biomphalaria. However, it was not possible to associate the presence of lectins in snail hemolymph with the susceptibility level to $S$. mansoni infection of the snail strain (Zelck et al. 1995, Johnston \& Yoshino 1996). Our results show that there were differences in the expression of haptens (glycoproteins or glycolipids) on the hemocyte membrane of different species or strains of Biomphalaria. These differences could result in greater capacity of hemocytes, from different strains, of recognizing and adhering to the parasite.
Corroborating this hypothesis, our results also demonstrate that $S$. mansoni infection produced dissimilar effects on the labelling pattern of circulating hemocytes by lectins in different snail strains. In B. glabrata, it was observed that there was a significant increase on the proportion of circulating hemocytes labelled by lectins, up to $72 \mathrm{~h}$ post-infection. Conversely, $5 \mathrm{~h}$ after $S$. mansoni infection, the hemocytes labelled by lectins nearly disappeared from the circulation of $B$. tenagophila Taim, a strain able to destroy sporocysts completely. Previous works (Bezerra et al. 1997, Martins-Souza et al. 2003) report a decrease in the total number of circulating hemocytes in B. glabrata or B. tenagophila at the first hours after infection. However, the results here presented indicate that hemocytes which are out of circulation in B. tenagophila Taim are the ones that express haptens for lectins, suggesting that these hemocytes could be retained in the site of infection, thus justifying the intense cellular reaction observed in these snails that would result in early parasite destruction.

\section{ACKNOWLEDGEMENTS}

To the Schistosomiasis Research Group staff, for the technical support in the experiments. To Mrs Vera de Paula Ribeiro for reviewing the text.

\section{REFERENCES}

Barraco MA, Steil AA, Gargioni R 1993. Morphological characterization of the hemocytes of the pulmonate snail Biomphalaria tenagophila. Mem Inst Oswaldo Cruz 88: 73-83.

Bayne CJ 1990. Phagocytosis and non-self recognition in in- 
vertebrates BioScience 40: 723-731.

Bezerra FSM, Nogueira-Machado JÁ, Chaves MM, Martins RL, Coelho PMZ 1997. Quantification of the number and phagocytary activity of hemocytes of resistant and susceptible strains of Biomphalaria glabrata and Biomphalaria tenagophila infected with Schistosoma mansoni. Rev Inst Med Trop São Paulo 39: 197-201.

Chernin E 1970. Behavioral reponses of miracidia of Schistosoma mansoni and other trematodes to substances emitted by snails. J Parasitol 56: 287-296.

Coelho PM, Carvalho OS, Andrade ZA, Martins-Sousa RL, Rosa FM, Barbosa L, Pereira CAJ, Caldeira RL, JannottiPassos LK, Godard AL, Moreira LA, Oliveira GC, Franco GR, Teles HM, Negrão-Corrêa D 2004. Biomphalaria tenagophila/Schistosoma mansoni interaction: premises for a new approach to biological control of schistosomiasis. Mem Inst Oswaldo Cruz 99:109-111.

Corrêa MCR, Coelho PMZ, Freitas JR 1979. Susceptibilidade de linhagens de Biomphalaria tenagophila e Biomphalaria glabrata a duas cepas de Schistosoma mansoni - (LE - Belo Horizonte - MG e SJ - São José dos Campos - SP). Rev Inst Med Trop São Paulo 21: 72-76.

Fryer SE, Bayne CJ 1996. Phagocytosis of latex beads by Biomphalaria glabrata hemocytes is modulated in a strainspecific manner by absorbed plasma components. Dev Comp Immunol 20: 23-337.

Fryer SE, Hull CJ, Bayne CJ 1989. Phagocytosis of yeast by Biomphalaria glabrata: carbohydrate specificity of receptors and a plasma opsonin. Dev Comp Immunol 13: 9-16.

Lysosomal enzyme actioities in susceptible and refractory sttrains of Biomphalaria glabrata during the course of infection with Schistosoma mansoni. J Parasitol 69: 10181026.

Granath Jr WO, Yoshino TP 1983. Lysosomal enzyme activities in susceptible and refractory strains of Biomphalaria glabrata during the course of infection with Schistosoma mansoni. J Parasitol 69: 1018-1026.

Granath Jr WO, Yoshino TP 1984. Schistosoma mansoni: passive transfer of resistance by serum in the vector snail, Biomphalaria glabrata. Exp Parasitol 58: 188-93.

Guaraldo AMA, Magalhães LA, Rangel HÁ, Pareja G 1981. Evolução dos esporocistos de Schistosoma mansoni (Sambon, 1907) em Biomphalaria glabrata (Say, 1818) e Biomphalaria tenagophila (D’Orbigny, 1835). Rev Saúde Pública 15: 436-448.

Guillou F, Mitta C, Dissous R, Pierce R, Coustau C 2004. Use of individual polymorphism to validate potencial funcional markes: case of a candidate lectin (Bgsel) differentially expressed in susceptible and resistant strains of Biomphalaria glabrata. Com Biochem Physiol 138: 175-181.

Hahn UK, Bender RC, Bayne CJ 2000. Production of reative oxygen species by hemocytes of Biomphalaria glabrata: carbohydrate-specific stimulation. Dev Comp Immunol 24: 531-541.

Johnston LA, Yoshino TP 1996. Analysis of lectin and snail plasma binding glycopeptides associated with the tegumental surface of the primary sporocysts of Schistosoma mansoni. Parasitology 112: 469-479.

Johnston LA, Yoshino TP 2001. Larval Schistosoma mansoni excretory-secretory glycoproteins (ESPs) bind to hemocytes of Biomphalaria glabrata (Gastropoda) via surface carbohydrate binding receptors. J Parasitol 87: 786-793.

Joky A, Matricon-Gondran M, Benex J 1983. Fine strutural differences in the amoebocytes of Biomphalaria glabrata. Dev Comp Immunol 7: 669-672.

Loker ES, Yui MA, Bayne CJ 1984. Schistosoma mansoni: Aglutination of sporocysts, and formation of gels on miracidia transforming in plasma of Biomphalaria glabrata. Exp Parasitol 58: 56-62.

Martins-Souza RL, Pereira CAJ, Coelho PMZ, Negrão-Corrêa D 2003. Silica treatment increases the susceptibility of the Cabo Frio strain of Biomphalaria tenagophila to Schistosoma mansoni infection but does not alter the natural resistance of the Taim strain. Parasitol Res 91: 500-507.

Matricon-Gondran M, Letorcart M 1999. Internal defenses of the snail Biomphalaria Glabrata - I. Caracterization of hemocytes and fixed phagocytes. J Invertebr Pathol 74: 224-234.

Paraense WL, Corrêa LR 1963. Variation in susceptibility of populations of Australorbis glabratus to a strain of Schistosoma mansoni. Rev Inst Med Trop São Paulo 5: 15-22.

Pellegrino J, Katz N 1968. Experimental chemotherapy of schistosomiasis mansoni. Adv Parasitol 6: 233-290.

Pereira CAJ 2005. Influência de Fatores Solúveis da Hemolinfa de Co-infecções com Angiostrongylus vasorum na Susceptibilidade de Biomphalaria tenagophila à Infecção por Schistosoma mansoni, MSc Thesis, Universidade Federal de Minas Gerais, Belo Horizonte.

Richards CS, Renwrantz LR 1991. Two lectins on the surface of Helix pomoatia haemocytes: a $\mathrm{Ca}^{2+}$ dependent, GalNacspecific lectin and a $\mathrm{Ca}^{2+}$ independent, mannose 6-phosphate-specific lectin which recognizes activated homologous opsonins. J Comp Physiol 161: 43.

Rosa FM, Godard AL, Azevedo V, Coelho PM 2005. Biomphalaria tenagophila: dominant character of the resistance to Schistosoma mansoni in descendants of crossbreedings between resistant (Taim, RS) and susceptible (Joinville, SC) strains. Mem Inst Oswaldo Cruz100: 19-23.

Santos MBL, Freitas JR, Corrêa MCR, Coelho PMZ 1979. Susceptibilidade ao Schistosoma mansoni de híbridos de Biomphalaria tenagophila do Taim, RGS, Cabo Frio, RJ, e Belo Horizonte. Rev Inst Med Trop São Paulo 21: 281-286.

Sminia T 1981. Structure and function of blood cells of gastropods. In Invertebrate Blood Cell, Acad Press, New York, $191 \mathrm{pp}$.

Souza CP, Borges CC, Santana AG, Andrade ZA 1997. Comparative histology of Biomphalaria glabrata, B. tenagophila, and $B$. straminea with variable degrees of resistance to Schistosoma mansoni miracidia. Mem Inst Oswaldo Cruz 92: 517-522.

Souza CP, Cunha RCP, Andrade ZA 1995. Development of Schistosoma mansoni in Biomphalaria tenagophila, Biomphalaria straminea and Biomphalaria glabrata. Rev Inst Med Trop São Paulo 37: 201-206.

Sullivan JT, Richards CS 1981. Schistosoma mansoni, NIHSM-PR-2 strain, in susceptible and nonsusceptible stocks of Biomphalaria glabrata: comparative histology. J Parasitol 5: $702-708$. 
Uchikawa R, Locker ES 1991. Lectin-binding propieties of the surfaces of in vitro- transformed Schistosoma mansoni and Echinostoma paraensei sporocysts. J Parasitol 77: 742748.

Van Der Knaap WPW, Loker ES 1990. Immune mechanisms in trematode-snail interactions. Parasitol Today 6: 175-182.

Yoshino TP 1976. The ultrastructure of circulating hemolymph cells of the marine snail Cerithidea californica (Gastropoda: Prosobranchiata). J Morphol 150: 148.

Yoshino TP, Boyle JP, Humphries JE 2001. Receptor-ligand interacions and celular cellular signalling at the host-para- site interface. Parasitology 123 (Suppl. SL): 43-57.

Yoshino TP, Cheng TC, Renwrantz LR 2001. Lectin and blood group determinants of Schistosoma mansoni: alteration following in vitro transformation of miracidium to mother sporocyst. J Parasitol 63: 818-824.

Zelck U, Becker W 1990. Lectin binding to cells of Schistosoma mansoni sporocysts and surrounding Biomphalaria glabrata tissue. J Invertebr Pathol 55: 93-99.

Zelck UE, Becker W, Bayne CJ 1995. The plasma proteins of Biomphalaria glabrata in the presence and absence of Schistosoma mansoni. Dev Comp Immunol 19: 181-194. 